\title{
"Garbage face": a managed care organisation's response to tobacco use
}

\author{
Sandra D Sandell
}

A banana skin for a hairdo, an anchovy for a nose, old orange peels for cheeks-what has become known as "Garbage face" is a provocative image. She certainly does not look anything like a Virginia Slims model. The image on the cover of this issue of Tobacco Control appeared on the Minnesota scene as part of a counter-tobacco advertisement created and sponsored by HealthPartners, a family of organisations that provide healthcare coverage and services to more than 700000 members. "Garbage face" is part of the creative response of a large, managed care organisation to the public health problem posed by tobacco.

The brainchild of George C Halvorson, the chief executive officer and president of HealthPartners, "Garbage face" counters the increase in smoking among Minnesota teenagers, especially girls. Says Halvorson, "Most kids are not impressed by the fact that they're likely to get emphysema at age 57. They smoke because they think it's cool to smoke. With "Garbage face", our message is that it is very uncool to smoke." This media campaign signalled the first time that this organisation had gone directly to young people with an advertising message on health. But rather than dwell on health effects 30 or 40 years in the future, the advertisements show the immediate social consequences of smoking-rejection.

That rejection is dramatically portrayed in the 30-second television counteradvertisement produced by Periscope, in which "Garbage face" appears. The MTVstyle $^{\star}$ commercial features a young girl puffing on a cigarette. With each puff her face is transformed into an animated face of garbage while she gabbles about her encounter with a boy she finds attractive. Here's the script:

Girl: "I mean there I was, walking down the hall and who comes around the corner ... Jason Evans. I almost died. What do I say? Hello, Jason. Good afternoon, Jason. You don't know me but I love you, Jason. I mean, he's coming right towards me, you know, like it was slow motion or something. We looked right into each others eyes ... he has the most beautiful eyes, and I say, 'Hi Jason' and he sort of stops and says . . . two words: 'breath mint'. I mean . . . what does that mean, anyways?"

Announcer: "It's simple. When you smoke, your breath stinks ... A message from HealthPartners."
Beginning in May 1996, the advertisements $\overrightarrow{\vec{\omega}}$


cable channel and during network televisionir programming popular with teens and preteens-programmes such as Who's the Boss?, Head of the Class, The Simpsons, and Bev-o erly Hills 90210. Over the course of the summer, the advertisements reached more than half the young people aged between two and 17 years in the media markets in which 3 they were shown. Radio stations aimed at ad youth audience featured a comparable series of commercials.

There was some criticism of the advertisements. One viewer complained thato they treated smoking too lightly. Death and disease, not just bad breath, he pointed out was the consequence of tobacco use. Buto research has shown that the fear of death and $\mathrm{Q}$ disease does not appear to motivate teenagers. $\overrightarrow{\overrightarrow{0}}$ And, as Earl Johnston, HealthPartners' manager of promotions communications points out, anecdotal evidence suggests that the advertisements resonated with theiro intended audience. Competitions had sprungo up between 10-12-year-old girls over whoô could recite the script the fastest. And oneô radio station reported that teenagers called $\overrightarrow{\bar{F}}$ requesting disc jockeys to replay the advertise-음 ments.

The media campaign has its origins in ai report issued by the Tobacco Initiative Task 3 Force appointed by Dr George Isham,o HealthPartners' medical director, and headed? by Dr Leif Solberg, a HealthPartners familyo physician with research interests in improving clinical systems. Adopted by the HealthPart-or ners' board of directors in December 1995, the 0 report committed the organisation to a N rigorous agenda for tobacco control thato included not only standards of clinical careo with vigorous efforts at tobacco cessation, but also public policy and community initiatives ${ }^{?}$ such as counter-advertising.

This agenda was revealed to members in the $\frac{\overrightarrow{0}}{\mathbb{D}}$ Spring 1996 issue of Discover, a graphically exciting magazine sent to all HealthPartners음 members. Devoted entirely to tobacco, this Discover issue contained predictable articleso such as "Here's how tobacco HARMS YOUR-


the task force's conclusion that public policy is ${ }^{?}$

$\star$ MTV $=$ Music Television, a television station featuring youth-oriented music videos. 
an effective way to counter tobacco, the magazine included articles supporting increased tobacco taxes as an effective way to deter tobacco use by young people, urging members to contact elected officials to reduce teen access to tobacco, and educating readers about the pernicious effects of tobacco advertising on children. In other words, the magazine provided its readers with useful health information and a rationale for a multifaceted tobacco control agenda.

To assure that this rationale reached those who shape public policy, HealthPartners' Corporate Communications Department mailed copies of this Discover and a colour storyboard of the "Garbage face" advertisement to providers, HealthPartners employees, and other Minnesota media. Accompanying letters pointed out that teenage smoking was rising and that HealthPartners' media campaign was an attempt to counter the tobacco industry's marketing efforts. The marketing department also scheduled the "Garbage face" advertisement during coverage of the political conventions of the United States Presidential campaign, programming typically watched by community leaders.

The HealthPartners campaign came at a time when the tobacco control movement in Minnesota was gaining in numbers and power. In 1994, the State of Minnesota and Blue Cross and Blue Shield of Minnesota jointly filed suit against the tobacco companies, accusing them of fraud and deception and asking for reimbursement for medical expenses. The suit enticed Attorney General Hubert H Humphrey III to take an active stand at the legislature in opposing the industry. During the legislative session that preceded the appearance of "Garbage face", HealthPartners and other providers of managed care in the state joined Humphrey and the traditional allies of tobacco control in opposing a bill introduced by allies of the tobacco industry that established minimal standards for licensing tobacco dealers and pre-empted local governments from setting higher penalties. The tobacco control movement showed its muscle in defeating this blatant attempt to frustrate a wave of local action. Commenting on the importance of the added strength of the tobacco control movement, Jeanne Weigum, president of the Association for NonsmokersMinnesota and a battle-scarred veteran in public policy efforts, captured the sentiments of Minnesota's tobacco control community in the state: "For too long the health community sat back and let the tobacco industry set public policy that affects not just the health of kids but the whole country. Having someone like HealthPartners insisting that health come first makes a huge difference."

In anticipation of a similar battle on youth access next year, the Minnesota Hospital and Healthcare Partnership (MHHP), a trade association representing the state's hospitals and managed care organisations, launched a campaign called STAT! (Stop Teen Access to Tobacco). STAT! encouraged hospital administrators and other healthcare providers to mobilise their communities to support local youth access ordinances. Nearly $40 \%$ of the MHHP members pledged to become involved in the campaign and by the end of October, five city councils had passed strong youth access ordinances and several others had begun to consider them. For its part, HealthPartners targeted nine communities. HealthPartners has clinics in four of these communities, and strong grassroots support in the other five.

The organisation's participation in this effort was consistent with the recommendations of its Tobacco Initiative Task Force. It acknowledged that reducing smoking entails changing the community environment to make it more supportive of those resisting pressures to use tobacco and of those wanting to quit. It supported strong legislation aimed at preventing youth access to tobacco. Pointing to the effect that a higher tobacco tax could have on the consumption rate, particularly among young people, the task force also supported an increase in the tobacco tax. This proposal may surface in 1997 if the legislature does not find funding needed for various legislative initiatives and programmes.

It is against this background of policy and media advocacy that HealthPartners' clinical interventions should be viewed. The goal of these interventions over the next decade is to reduce smoking prevalence among HealthPartners' members by $50 \%$. To this end the task force recommended developing and maintaining clinical office systems that assure (a) the routine identification of all tobacco users and those exposed to secondhand smoke; (b) the delivery of appropriately tailored cessation messages and interventions; and (c) the measurement of the effectiveness of interventions.

Addressing tobacco use was implicit in the Partners for Better Health program, introduced in 1994. At that time HealthPartners set six ambitious goals and has since added two more.

- Reduce by $25 \%$ the number of heart disease events among members.

- Screen $90 \%$ of the members at a high risk for diabetes and reduce complications attributable to the disease.

- Reduce infant and maternal complications among members.

- Reduce by half new dental cavities among dental members in all age groups.

- Increase from $75 \%$ to $95 \%$ the proportion of children in the system fully immunised against childhood disease by age 2 .

- Reduce by half the cases of breast cancer that reach an advanced state before being detected.

- Reduce the number of serious childhood injuries among members.

- Help identify members who may be victims of domestic abuse and link them to appropriate services and prevention resources.

The Tobacco Initiative Task Force explicitly spelled out that reducing smoking among members was essential to achieving the Partners for Better Health goals. They pointed out that $20-30 \%$ of cardiac disease and death could be attributed to tobacco. Targeting 
women at the first sign of pregnancy, HealthPartners could see a reduction in low birth weight and premature births of $5 \%$ to $10 \%$. Targeting female smokers before they became pregnant would produce additional cessation and prepare those who did not quit for quitting when they become pregnant. If all patients were assessed for their smoking status and smokers for their readiness to quit, smoking rates would fall even more.

Clinical practices are not changed overnight. Unless they are provided with tools for assessing and counselling patients, care givers may be reluctant to provide gratuitous advice. Nor will they record in charts whether they have given advice on tobacco use unless they are provided with an easy means of doing so. The tasks ahead are making providers comfortable with counselling members and presenting members with a large repertoire of cessation programmes: programmes that meet their needs, fit into their busy schedules, and mesh with their readiness to change. Telephone counselling, interactive computer programs, programmes based in the worksite, and short preparatory classes, are being considered to supplement an array of more traditional approaches.

In the meantime, the "Garbage face" campaign continues. Its popularity encouraged the marketing staff to design book covers and temporary tattoos and to find an effective way to distribute them. They saw their opportunity in partnering a television station at the Minnesota State Fair. Each year about 1.5 million people, 210000 of them under the age of 18 , attend the Great Minnesota Get Together. Held just before the beginning of the school year, the State Fair is an ideal place to distribute book covers that include health messages. Drawn by the music emanating from the TV station's booth, nearly 40000 young people picked up book covers, and 60000 walked away with temporary tattoos. A second wave of counter-advertisements, begun as school started, is entitled "Teen kiss". To target slightly older teens, the advertisements feature a boy and girl talking at a drive-in restaurant. When the boy discovers that the girl smokes, he switches his attention to one of the girl's friends.
Another product of Halvorson's imagination appeared as an insert in the Autumn 1996Discover. "The sure-fire fifty-day way to stop? smoking" features a smoke-spewing dragono bound with rope, and presents 50 tips for quelling the dragon of nicotine addiction. The pullout unfolds to make an eye-catching cessa $\overrightarrow{\vec{c}}$ tion calendar poster three feet $(91 \mathrm{~cm})$ long This calendar appeared in Minnesota's twof largest newspapers in November, just in times for D-Day (Don't Smoke Day), Minnesota'\$ version of the Great American Smokeout. An cessation calendar aimed at teens is being test $=$ marketed.

"Garbage face" will be visible for a long time. Very soon teen leaders in the Minnesotas Coalition for a Smoke Free Society 2000's "Kick Butts" programme will receive teeshirts் imprinted with the image, teeshirts they cariv wear when they teach other young people, tes-0 tify before city councils, or organise tobacco ${ }^{\circ}$ initiatives in their communities. The shirts wil $\square$ serve as prizes for a school-based tobacco prevention contest. Moreover marketing staff have® made the campaign available at cost tog managed care organisations throughout the country.

The whole tobacco initiative supports HealthPartners' attempt at positioning itself ing the Upper Midwest as the managed cares organisation that takes its mission seriously "to improve the health of our members and the community". It has allowed the organisation to mesh its marketing message with it $\overrightarrow{\vec{S}}$ commitment to community health, commitment perhaps best summarised by $\mathrm{D}$ Dave Klevan, one of the physicians responsible. for implementing and researching the standards of care relating to tobacco use: "We् probably have more lobbyists working on tobacco control and more nurses working on smoking cessation than any managed care organisation in the state." Even if this proves to be an exaggeration, there is no doubt tha $B$ HealthPartners has involved virtually every part of the organisation-from the CEO to marketing, communications, health promo-o tion, physicians, nurses, government relations and quality control-to quelling the tobaccos. dragon.

\section{Note to readers}

We hereby solicit your ideas and contributions for future covers of Tobacco Control. As with previous covers, we would like future covers to be colourful and creativewith a tobacco control theme. Original artwork, anti-tobacco posters, photographs, and cartoons may all be considered. Material with an international flavour would be particularly desirable. A cover essay will generally appear in each issue to provide appropriate background information and commentary on the cover.

Please send ideas and submissions (original or high-quality, camera-ready photographs) to the editor at the address on the inside front cover.-ED 